\title{
Partidos y elecciones presidenciales del 2023 en Paraguay ${ }^{1}$
}

\section{Parties and presidential elections of 2023 in Paraguay}

Fernando Martínez ${ }^{2}$ y Lorena Soler ${ }^{3}$

\section{Resumen}

Los bicentenarios partidos políticos de Paraguay continúan siendo los actores privilegiados de la organización de la disputa política electoral. En este artículo nos proponemos identificar la construcción de nuevas reglas formales e informales de competencia que, hasta nuestros días, han marcado los límites a la transición a la democracia: la fórmula D'Hondt, el juicio político, la no reelección presidencial, el cuoteo político y el voto de censura. Partimos de la hipótesis de que la paridad de las fuerzas internas de la Asociación Nacional Repúblicana (ANR), tras la transición a la democracia, provocó que ese partido funcione como partido de Gobierno y de oposición al mismo tiempo. Finalmente, ensayamos algunas alternativas del escenario de las elecciones presidenciales de 2023.

Palabras clave: democracia; partidos políticos; Paraguay; elecciones 2023

\begin{abstract}
The bicentennial political parties in Paraguay are privileged actors in the organization of the electoral political dispute. In this article, we propose to identify the construction of new formal and informal rules of competition that have delimited the transition to democracy up to this days: the D'Hondt formula, the impeachment, presidential non-reelection, distribution of public offices and voting censorship. The hypothesis is that the parity of the internal forces of the ANR, after the transition to democracy, made the ANR function as a government and opposition party at the same time. Finally, it rehearses some alternatives for the 2023 presidential election scenario.
\end{abstract}

Keywords: democracy; political parties; Paraguay; elections 2023

\footnotetext{
1 Trabajo recibido el 30/03/2021. Aceptado el 09/06/2021.

${ }^{2}$ Universidad de Buenos Aires. Consejo Nacional de Ciencia y Tecnología (Paraguay). Contacto: fmartinezes@gmail.com

${ }^{3}$ Universidad de Buenos Aires. Consejo Nacional de Investigaciones Científicas y Técnicas. Contacto: lorenamarinasoler@gmail.com
} 


\section{Introducción}

Una de las características centrales de la historia de Paraguay ha sido la presencia de los partidos políticos a la hora de organizar la vida política, aun cuando -paradójicamente- la inestabilidad, el orden social y los largos períodos autoritarios han sido la clave distintiva. El bipartidismo, iniciado en 1887 con la aparición del Partido Liberal y el Partido Colorado -posteriormente a la promulgación de la Constitución liberal y posbélica de 1870-, ha perdurado hasta el presente y sigue siendo un actor central de la vida púbica: si solo nos remetimos al último medio siglo, los partidos fueron uno de los elementos de legitimidad de la dictadura stronista y de la transición a la democracia, tanto como del golpe de Estado «parlamentario» a Fernando Lugo, en 2008, y del arribo de la «nueva derecha empresarial» con Horacio Cartes.

Claro que, como todas las instituciones, han sufrido los avatares de la época y sus transformaciones deben ser apreciadas. En este trabajo nos proponemos pensar los partidos de cara a las elecciones presidenciales del 2023, haciendo foco en el partido hegemónico (Partido Colorado-ANR-) y en sus dos fuerzas internas importantes: el Movimiento Añetete, del actual presidente de la república, Mario Abdo, y el Movimiento Honor Colorado, liderado por el expresidente Horacio Cartes. Asumimos que dominarán la escena electoral y serán los nudos centrífugos desde los que se organice el conflicto político en los años venideros.

Para cumplir con dicho objetivo, el trabajo se organiza en dos coordenadas: repasa y caracteriza el orden social y político stronista y aborda sus consecuencias, en el sistema político y partidario, tras su caída. Parte de la hipótesis de que, tras la transición a la democracia, la paridad de las fuerzas internas de la ANR provocó que ese partido funcione, simultáneamente, como partido de gobierno y de oposición tras generar nuevas reglas distributivas de poder, propiciar la competencia interna de sus movimientos y negociar y cooperar con los movimientos y los demás partidos de la oposición para desbalancear el poder al interior de su propia estructura. En razón de esto, es posible identificar la construcción de nuevas reglas formales e informales de competencia que, hasta nuestros días, le han puesto límites a la transición a la democracia: la fórmula D'Hondt, el juicio político, la no reelección presidencial, el cuoteo político y el voto de censura. Finalmente, ensaya algunas alternativas para pensar el escenario electoral del 2023. 


\section{Orden social y sistema político desde la crisis del stronismo hasta la transición a la democracia}

El primer rasgo que prevalece en una mirada acerca de la vida política paraguaya es la alternancia entre largos períodos autoritarios y etapas de alta inestabilidad política. Tal inestabilidad se torna más sugestiva si se la confronta con la temprana aparición de ciertos elementos de la democracia política, como las pretensiones universalizantes del derecho al sufragio (1870), los legendarios y duraderos partidos políticos (1887) e, incluso, el predominio de la élite política sobre la élite militar. Asimismo, a excepción de las experiencias políticas más autónomas como la Revolución Febrerista (1936) y los inicios de la dictadura del militar Higinio Morínigo (1940-1946) o la novedosa experiencia política partidaria del Frente Guasu con el arribo de Fernando Lugo a la presidencia de la nación, la vida política transcurrió entre dos partidos políticos: el Partido Liberal y el Partido Colorado o ANR -O por facciones intrapartidarias de estos-. Además, es dable destacar que, hasta 2008, el Partido Colorado fue el partido más antiguo en el Gobierno, en América Latina, superando incluso al PRI mexicano (De Riz, 2007).

La llegada de la «dictadura más larga» a Paraguay, el régimen stronista (1954-1989), tampoco fue ajena a la participación de los partidos políticos, que otorgaron -según las etapas- un ropaje democrático al régimen autoritario. En rigor, el arribo de Alfredo Stroessner, elegido presidente por el Partido Colorado en 1954 tras un golpe de Estado debe leerse en el contexto de los años 1950, de reconfiguración del patrón mundial del capitalismo y de los irrecusables cambios que se expresaban en muchos ordenes políticos de la región. ${ }^{4}$ En ese contexto, el stronismo significó una experiencia autoritaria que comprendió una modalidad de cambio social mediante el empleo de formas dictatoriales de regulación del sistema político y cooptación de clases sociales y élites políticas. La construcción del régimen bajo un despotismo republicano (Delich, 1981), a partir de un proceso de modernización conservadora (Moore, 2002), se asentó sobre algunos pilares básicos: la reorganiza-

\footnotetext{
${ }^{4}$ Este irrecusable cambio se expresaría en el Bogotazo de Colombia (1948), la revolución de Bolivia (1952) y las reformas que el Gobierno revolucionario de Jacobo Arbenz estaba llevando a cabo en Guatemala desde su elección en 1951. También en el suicidio de Vargas, en Brasil (1954); el golpe de Estado de la Argentina (1955), la victoria del Partido Blanco de Uruguay, por primera vez en el siglo XX, y la llegada al poder en Chile del derechista Arturo Alessandri (1958).
} 
ción del sistema político (modificaciones legales y constitucionales), la participación/cooptación de las élites políticas a través de los partidos (o transformismo, en la conceptualización gramsciana), la mutación del Partido Colorado en partido Estado (que además brindó el andamiaje institucional para los sucesivos triunfos electorales de Stroessner), la partidización de las Fuerzas Armadas y la militarización del partido gobernante (con el nombramiento de los generales como presidentes de la Junta de Gobierno del partido) y un sistema de represión, puesto en acción en el marco del Plan Cóndor.

Parte de la legitimidad política del stronismo se asentó en exhibir -nacional e internacionalmente- un funcionamiento «democrático» del régimen político, que se modificaría según las etapas y las coyunturas históricas, aunque, una vez asegurada la primera reelección -para el período 1958-1963-, el Congreso fue cerrado. Para su tercera reelección (1963), Alfredo Stroessner fomentó y permitió la presentación de los partidos, o de facciones de ellos, cuya participación era necesaria con el horizonte en ciernes de la reforma constitucional..$^{5}$ De esta manera, la Asamblea Constituyente de 1967 fue elegida a través de mecanismos electorales y contó con la presencia de los partidos políticos opositores más representativos (el Partido Liberal Radical, el Partido Revolucionario Febrerista y el Partido Liberal). A menos de un año, la elección que permitió su cuarto mandato (1968-1973), con todos los partidos políticos devueltos a la legalidad, se realizó sin mayores inconvenientes para el triunfo oficialista, y marcó, en la hipótesis de Jorge Lara Castro (1987), el inicio de la consolidación de la dictadura bajo la forma de un gobierno de democracia representativa.

Sin embargo, los inicios de la década de 1970 trajeron un viraje político importante para la región, que coincidió con la ruptura, entre los años 1971 y 1972, de las relaciones de Paraguay con los Estados Unidos. Así, tras las elecciones presidenciales de 1973, el stronismo comenzó a

${ }^{5}$ A partir de 1963 se incorporó el Partido Liberal al proceso eleccionario, y el Partido Revolucionario Febrerista lo haría a partir de las elecciones municipales de 1965. Un buen ejemplo de la manipulación sobre la oposición lo brinda el papel desempeñado por el Partido Liberal (PL). En 1962, la dictadura reconoció al PL y en 1967 al Partido Liberal Radical (PLR), otro grupo dentro del Partido Liberal que no coincidía con los separatistas; ambos partidos se encontraban en el Parlamento y participaban de las elecciones. Cuando en 1977 el PL y el PLR acordaron no presentarse al proceso electoral, el general Alfredo Stroessner pactó con un grupo opositor dentro del PL, por lo cual los abstencionistas, para diferenciarse, pasaron a llamarse Partido Liberal Radical Auténtico, denominación que conservan hasta hoy. 
clausurar cada vez más el espacio para la participación partidaria, por lo que el Partido Revolucionario Febrerista (PRF) decidió no participar más de los comicios, medida que adoptó en 1977 una parte del liberalismo. Este viraje culminó con la enmienda constitucional que modificaba el art. 173 de la Constitución Nacional, que permitió la reelección indefinida. A partir de ese momento, un sector del liberalismo, agrupado en el novel Partido Liberal Radical Auténtico (PLRA), se apartaría del Partido Liberal (PL) y del Partido Liberal Radical (PLR) y, junto con otros partidos y fuerzas políticas, decidirían no presentar candidatos y plegarse abiertamente a un posicionamiento abstencionista frente a los siguientes comicios, que se realizarían en 1978, 1983 y 1988.

La transición a la democracia y el empate de las fuerzas internas del ANR. Las nuevas reglas del juego político

A partir de octubre de 1982, con el fin de la dictadura boliviana, se inició en el Cono Sur un proceso de recuperación de la democracia política que prosiguió en Argentina, Uruguay, Brasil, Chile y Paraguay. En este último país, el resquebrajamiento público de «la unidad granítica» del Partido Colorado, conducido por Alfredo Stroessner, se produjo luego del VI Congreso de la Juventud Colorada, celebrado en 1984, momento en el que emergieron las corrientes internas de la ANR que iban a ser a ser conocidas como militantes y tradicionalistas. Además, durante los años 1980, fueron surgiendo otros movimientos menores que, junto a la disidencia exiliada de las décadas anteriores, hacían del Partido Colorado una arena política cada vez más fragmentada. Finalmente, esa ruptura se consolidó en la convención colorada de 1987 y, en forma definitiva, durante el derrocamiento de Alfredo Stroessner, en 1989. 


\section{Tabla 1: Sectores del Partido Colorado a fines de los años 80}

\begin{tabular}{|l|l|}
\hline \multicolumn{1}{|c|}{ Tiempo } & \multicolumn{1}{|c|}{ Sectores del Partido Colorado } \\
\hline Purga de 1956 & $\begin{array}{l}\text { El líder colorado Epifanio Méndez Fleitas es enviado al exilio. } \\
\text { Más tarde participa del MOPOCO y, en 1973, crea la ANRER. }\end{array}$ \\
\hline Purga de 1959 & $\begin{array}{l}\text { Guionistas, chavistas y epifanistas. Creación del MOPOCO. Sus } \\
\text { miembros vuelven del exilio en 1983. Crean el MOPOCONA en } \\
\text { 1987. Con la caída del stronismo se vuelven a insertar en el } \\
\text { Partido Colorado. }\end{array}$ \\
\hline $\begin{array}{l}\text { Movimientos nacidos en los } \\
\text { años ochenta }\end{array}$ & $\begin{array}{l}\text { 1) Ético y Doctrinario, 2) MIC, 3) Tradicionalistas, } \\
\text { 4) Militantes, 5) Nacional y Popular. }\end{array}$ \\
\hline $\begin{array}{l}\text { Movimientos en disputa } \\
\text { dentro de la arena colorada. } \\
\text { Convención colorada de 1987 }\end{array}$ & \begin{tabular}{l} 
1) Tradicionalistas, 2) Militantes, 3) Nacional y Popular. \\
\hline
\end{tabular} \\
\hline
\end{tabular}

Fuente: Martínez Escobar (2021)

A partir del proceso de la transición a la democracia iniciado en 1989, los movimientos internos de la ANR quedaron en equilibrio de fuerzas y ninguno recuperó el dominio total del partido, aun aliándose a las Fuerzas Armadas. Es decir, los distintos sectores se encontraron en una situación de relativa paridad que los conduciría a generar nuevas reglas distributivas de poder, a propiciar la competencia interna de sus movimientos y a negociar y cooperar con los movimientos y partidos de la oposición para desbalancear el poder al interior del Partido Colorado. Por lo que, durante este proceso, la ANR actuó como partido de Gobierno y de oposición al mismo tiempo.

Si bien desde 1960 hasta 1984 la unidad colorada estuvo subordinada y supeditada a la conducción de Alfredo Stroessner y fue la constante que dirigió la política paraguaya, claramente, a partir del su derrocamiento, lo que primó fue el equilibrio de debilidades entre las fuerzas políticas. A su vez, esto desembocó en la construcción de nuevas reglas formales e informales de competencia. Específicamente, tres reglas formales y dos informales estructuraron la competencia político-partidaria en los años 1990 y gran parte de los años 2000. En el grupo de las formales encontramos la fórmula $\mathrm{D}^{\prime} \mathrm{H}$ Hondt, el juicio político y la no reelección presidencial, en tanto que del lado de las reglas informales ubicamos el cuoteo político y el voto de censura. 


\section{Tabla 2: Reglas formales e informales}

\begin{tabular}{|c|c|c|}
\hline Regla & Formal & Informal \\
\hline Proporcional & Fórmula D’Hondt & Cuoteo político \\
\hline $\begin{array}{c}\text { Poder destituyente del Poder Legislativo sobre el } \\
\text { Poder Ejecutivo }\end{array}$ & Juicio político & Voto de censura \\
\hline $\begin{array}{c}\text { Período de mandatos presidenciales de cinco años, } \\
\text { no reelegibles en ningún caso, ni siquiera con } \\
\text { alternancia }\end{array}$ & $\begin{array}{c}\text { La no reelección } \\
\text { presidencial }\end{array}$ & No tiene \\
\hline
\end{tabular}

Fuente: Martínez Escobar, 2021

Cuando cayó Alfredo Stroessner, su reemplazante, el general Andrés Rodríguez -también colorado- intentó conducir el poder político institucional poniéndose al frente de la histórica alianza entre el Partido Colorado y las Fuerzas Armadas. Sin embargo, lejos de lograrlo, se encontró rápidamente con un equilibrio de fuerzas débiles entre los distintos sectores del coloradismo, que para desbalancear el poder necesitó aliarse a sectores de la oposición en el Congreso. En ese momento, el Movimiento Tradicionalista -conducido por Luis María Argaña y los históricos dirigentes Juan Ramón Chaves y Edgar L. Ynsfrán- pretendió controlar la Junta Electoral Central (JEC), antecesora del Tribunal Superior de Justicia Electoral, colocando solo a sus propios miembros en su conducción, lo que implicaba dejar fuera de la JEC a los otros movimientos internos de la ANR. En respuesta, el resto de los movimientos colorados, que incluía a los «excontestarios» y a la «generación intermedia», se unió a los partidos políticos de la oposición en la Cámara de Diputados y, con once votos del PLRA y dos del PRF, frenó las intenciones de los tradicionalistas de tener un control total sobre el principal órgano electoral. En otras palabras, los partidos de la oposición aportaron los votos decisivos para dirimir una disputa interna del partido gobernante.

Es posible afirmar entonces que, en 1989, se inició un modo de funcionamiento que sería perdurable en el tiempo y que explicaría también tanto la perdurabilidad del bipartidismo como la hegemonía del Partido Colorado desde 1989 hasta 2008: la cooperación entre los movimientos internos de la ANR y los partidos de la oposición para inclinar la balanza al interior del partido hegemónico. El empate de fuerzas más la incertidumbre del nuevo tiempo produjeron el incentivo necesario para 
la creación, la implementación y el mantenimiento de reglas proporcionales de distribución del poder político institucional a través de la fórmula D'Hondt, con listas cerradas y bloqueadas, que reemplazó al sistema de mayoría con prima, del régimen stronista.

A su vez, esta fórmula proporcional se aplicó a las competencias electorales en todos los niveles. Es decir, se utilizó la fórmula D’Hondt para repartir las bancas en el Congreso y en las concejalías municipales y departamentales, para distribuir las cuotas de poder institucional al interior de los partidos y para la elaboración final de las listas que representarían a los partidos en las elecciones a cualquier nivel. ${ }^{6}$ De esta forma, los partidos políticos que pugnaban por cargos proporcionales se vieron en la situación de tener que incluir en una única lista a los representantes de los diferentes movimientos internos, y los candidatos de las distintas facciones pasaron a ser aliados electorales obligados al mismo tiempo que enemigos políticos. ${ }^{7}$ En consecuencia, en la mayoría de las ocasiones, los distintos movimientos colorados armaron alianzas extraelectorales con los partidos de la oposición para desbalancear la disputa interna de fuerzas al interior de la propia ARN.

En la primera mitad de los años 1990, el nuevo sistema pluralizó la competencia política, terminó incentivando la división del poder político interno dentro de la ANR y permitió el fortalecimiento del sistema de partidos frente a las Fuerzas Armadas así como la distribución de ese poder político a nivel nacional.

Además, como ejemplificamos antes, se inició una nueva forma de cooperación y competencia entre los movimientos internos del Partido Colorado y los partidos de la oposición, lo que a su vez condujo a la creación de la regla informal del «cuoteo político», que fue una de las llaves de acceso de los partidos políticos de la oposición a la dirección de las instituciones gubernamentales -luego de muchas décadas de ausencia- y, a su vez, contribuyó a expulsar a los militares del poder político institucional en marzo de $1999 .{ }^{8}$

\footnotetext{
${ }^{6}$ El sistema D’Hondt también se utiliza para las elecciones de cualquier organización intermedia.

${ }^{7}$ Esta situación afectó a todos los partidos políticos.

${ }^{8}$ Los partidos políticos y los movimientos internos del Partido Colorado tenían el control político institucional del Poder Judicial, del Poder Legislativo y de varias instituciones y organismos del Estado; en este contexto ocurrió el último avance del sistema de partidos sobre el sector colorado militar, que controlaba al Poder Ejecutivo. En efecto, en marzo de 1999 fue asesinado Luis María Argaña mientras la Corte Suprema de Justicia declaraba
} 
En efecto, la nueva Constitución Nacional de 1992, además de modificar la composición de varias de las instituciones existentes y de conceder mayor peso al Poder Legislativo en desmedro del Ejecutivo, creó una serie de nuevas instituciones que propiciaron el contexto para que el nuevo sistema de competencia y cooperación de partidos se pusiera en marcha.

De hecho, la presidencia del colorado Juan Carlos Wasmosy (19931998) se inauguró con una notable dependencia del Congreso, dado que su partido estuvo por primera vez, en varias décadas, en minoría frente a la oposición en la Cámara de Diputados y en la de Senadores, además de que una parte importante de la bancada de la ANR, en ambas cámaras, fuera conducida por el principal movimiento opositor dentro del mismo partido oficialista, el Movimiento de Reconciliación Colorada, con Luis María Argaña. Asimismo, se profundizó el cuoteo político como regla informal, es decir, la concesión de una porción de poder político institucional a un partido o un movimiento político en función de un acuerdo entre los mismos partidos con bancas parlamentarias.

En este sentido se expresaba Julio César Franco ${ }^{9}$, uno de los principales dirigentes políticos del PLRA, que llegó a vicepresidente de Paraguay:

Hay que tener en cuenta que la mayoría del Partido Liberal que venía desde el 40 estando fuera de los puntos neurálgicos del poder veían que podía haber una posibilidad de ir acercándose al poder, porque con el Pacto de Gobernabilidad, por ejemplo, se permitió que de nueve miembros de la Corte Suprema de Justicia vayan tres liberales (...). El partido, de nueve que no tenía nada ihacía decenios! De repente coloca tres (...). La Justicia Electoral quedó constituida con un colorado, un liberal y un independiente (...) y comenzaron a aparecer liberales en la carrera judicial y también embajadores (Yore, 2015, p.222)

Entonces, la oposición, a partir de los años 1990-hasta el año 1989 había estado casi completamente fuera del reparto del poder político

\footnotetext{
inconstitucional la liberación del general Lino Oviedo (esta liberación había sido ordenada por el presidente de la república Raúl Cubas Grau) y el Congreso analizaba un juicio político al presidente a raíz de dicha liberación. A su vez, por estos hechos la gente se volcó a las calles y varios jóvenes fueron asesinados en las plazas durante las manifestaciones. Finalmente, Cubas Grau renunció al cargo de presidente y se disolvió la última alianza que representaba al pacto colorado-militar del 13 enero de 1947.

${ }^{9}$ Expresidente del PLRA y exvicepresidente de Paraguay.
} 
institucional-, se constituyó en una fuerza central en el Congreso y el Poder Judicial. La dinámica que se desarrolló durante esa década y gran parte de los 2000 produjo reglas distributivas de poder, tanto a nivel partidario como al interior de los mismos partidos, que permitirian la victoria electoral del mencionado Julio César Franco para la vicepresidencia de la república en el año $2000^{10}$ y de Fernando Lugo para la presidencia en el 2008.

\section{La no reelección presidencial y la aparición de Horacio Cartes, el outsider de la política}

La no reelección presidencial sin alternancia ${ }^{11}$ es un pacto mordaza que las élites políticas sellaron en la constitución de 1992 y ha funcionado, junto con la incorporación del juicio político y el reemplazo del estado de sitio por el estado de excepción, como uno de los núcleos centrales del pacto democrático de 1989 (Prego, 2019). Debe parte de su origen a las disputas internas del Partido Colorado y, además de contribuir a dar forma al sistema de partidos, ha sido una norma central para establecer una regla de competencia partidaria que sigue vigente y que varios presidentes paraguayos han querido cambiar sin éxito. El último intento fue el del entonces presidente Horacio Cartes en el año 2017 y terminó con el incendio del Congreso paraguayo y el asesinato de un miembro del PLRA dentro de su propio local partidario a manos de la Policía Nacional. Desde la transición a la democracia, «la prohibición de la reelección no cuestionó la no alternancia en la dirección del Gobierno del Partido Colorado y, cuando la misma se produjo, se llevó a cabo un juicio político que se tradujo en el golpe de Estado que obturó dicha posibilidad histórica»(Prego, 2019, p.12). Esta regla de no reelección ha servido tanto para facilitar el acceso a la presidencia de Horacio Cartes en 2013 como para impedir su continuidad en 2018.

En términos de competencia partidaria interna, la regla de no reelección, por un lado, genera una reducción del apoyo al presidente por parte de los líderes partidarios y sus movimientos durante el último tra-

\footnotetext{
${ }^{10}$ Sobre la base de la escisión de la ANR con la creación partidaria de UNACE, liderado por el exgeneral Lino Oviedo.

${ }^{11}$ La regla impide la reelección del presidente en el mismo cargo o su elección en cualquier otro.
} 
mo de su mandato quinquenal y, por otro, incentiva a que las fuerzas políticas se realineen con los sectores en ascenso. Esto es factible de contrastar entre el 2006 y 2008, cuando el presidente de la república Nicanor Duarte Frutos perdió el apoyo de su vicepresidente, Luís Alberto Castiglioni, e intentó sin éxito cambiar la regla de no reelección. Finalmente tuvo que promover la candidatura de Blanca Ovelar para las elecciones presidenciales de 2008, para dar continuidad a su movimiento político, mientras que Castiglioni formaba su propio movimiento dentro del Partido Colorado y casi derrotaba a la candidata oficialista. Finalmente, en la arena política nacional, Blanca Ovelar fue vencida electoralmente por la Alianza Patriótica para el Cambio, liderada por Fernando Lugo, y el Partido Colorado perdió el control sobre los recursos institucionales por primera vez desde 1947.

En este escenario de ausencias y derrotas para la ANR, surgió la figura del empresario Horacio Cartes, quien se constituyó en el nuevo líder del partido, sustentado con recursos económicos propios que sustituyeron a los institucionales y económicos provenientes del Estado. Horacio Cartes -hasta su candidatura se había mantenido al margen de la política formal y votó por primera vez cuando él fue su propio candidato a presidente de la república- rápidamente aprovechó el espacio que los partidos tradiconales dejaban a la representación política y la decadencia de los movimientos internos del Partido Colorado. Una crisis del sistema politico que se cristalizó en el periodo 2008-2013, con el ascenso de Fernando Lugo, el golpe de Estado y la presidencia del liberal Federico Franco. Tras cambiar las reglas para poder ser candidato y ganar las elecciones internas por un amplio margen, Horacio Cartes fue electo presidente en un escenario en el que el candidato no colorado con mayor capacidad para atraer votos colorados -Lino Oviedo- murió en un accidente aéreo y el resto de la oposición política transitaba una profunda crisis producto de la destitución de Fernando Lugo, ocurrida en 2012.

\section{Los juicios políticos, el voto de censura y la coyuntura de cara a las elecciones presidenciales de 2023}

Normalmente, en los sistemas presidenciales, el Poder Ejecutivo solo puede ser removido por un juicio político, ya que tanto el presidente como los legisladores son electos de manera directa por el pueblo, es decir, el origen del mandato presidencial no depende del Congreso (por 
lo mismo, tampoco el Ejecutivo puede disolver al Poder Legislativo). En resumen, ninguno de los dos puede ser removido por el otro sin causa ni el debido proceso. En cambio, en los sistemas parlamentarios, el Ejecutivo deviene del Legislativo. El jefe de Gobierno es un parlamentario designado por los miembros de la cámara baja y como tal, en caso de perder el apoyo necesario para gobernar, es removido de su cargo por el solo hecho de no tener ya los votos de apoyo sobre los que se sustentaba su mandato.

En Paraguay, el juicio político es una herramienta establecida por la Constitución Nacional dentro de un sistema presidencialista. ${ }^{12}$ Es decir, el juicio político es la única forma legal de remover al presidente de la República. Sin embargo, en los hechos, esta regla formal es utilizada a través de la regla informal del voto de censura de los sistemas parlamentarios. En Paraguay, para dar inicio legalmente a todo juicio político, se precisa establecer una serie de acusaciones que se plasma en un libelo acusatorio. Todos los actores políticos saben que la destitución de los presidentes se pone en funcionamiento a partir de la regla formal del juicio político, pero que se ejerce informalmente a través del voto de censura del sistema parlamentario, lo cual implica que, si el Congreso tiene los votos necesarios para destituir al presidente, este será destituido independientemente de la causa que pudiese motivar el hecho. En Paraguay, como ha indicado Julien Demelenne (2021), el golpe por la via parlamentaria significa la reproducción de un esquema de dominación, pero también de un cambio social: la tensión entre concretar golpes de Estado, que rompen con la legitimidad institucional, y materializar elecciones para ratificar la institucionalidad. Se aplicó en cuatro oportunidades. El primer caso fue el de Raúl Cubas Grau (1999), tras el asesinato del por entonces vicepresidente de la nación Luis María Argaña (23 de marzo), que desencadenó una ola de manifestaciones y protestas conocida como la «Masacre del Marzo Paraguayo»; sin embargo, el

12 Artículo 225 del Juicio Político. El presidente de la República, el vicepresidente, los ministros del Poder Ejecutivo, los ministros de la Corte Suprema de Justicia, el fiscal general del Estado, el defensor del Pueblo, el contralor general de la República, el subcontralor y los integrantes del Tribunal Superior de Justicia Electoral, solo podrán ser sometidos a juicio político por mal desempeño de sus funciones, por delitos cometidos en el ejercicio de sus cargos o por delitos comunes. La acusación será formulada por la Cámara de Diputados, por mayoría de dos tercios. Corresponderá a la Cámara de Senadores, por mayoría absoluta de dos tercios, juzgar en juicio público a los acusados por la Cámara de Diputados y, en caso, declararlos culpables, al solo efecto de separarlos de sus cargos, En los casos de supuesta comisión de delitos, se pasarán los antecedentes a la justicia ordinaria. 
proceso no pudo culminarse, dado que el presidente presentó antes su renuncia. El segundo fue el del presidente Luis González Macchi, que no prosperó porque no se logró la mayoría en la Cámara de Senadores; el tercero involucró a la Corte Suprema de Justicia, pues el pedido de juicio recayó sobre tres de sus miembros (2003), y el cuarto, finalmente, fue el aplicado y logrado contra Fernando Lugo (2012).

En rigor, si un movimiento político controla el caudal necesario de votos de las cámaras legislativas para llevar adelante un juicio político tiene el poder para mantener o remover al presidente de la república, sin importar realmente aquello que motive el proceso de destitución. Esto es exactamente lo que ocurre en la coyuntura actual entre el Movimiento Honor Colorado, liderado por el expresidente Horacio Cartes (20132018), y el actual presidente de la república Mario Abdo (2018-2023), del Movimiento Añetete.

El movimiento político de Horacio Cartes controla la Cámara de Diputados y, desde esa posición, lo ha puesto al presidente Mario Abdo (2018-2023) al borde de dos juicios políticos: en 2019, a meses del inicio de su Gobierno, y en marzo de 2021, en un escenario crítico con manifestaciones callejeras en el contexto de la pandemia.

Esto implica que por primera vez asistimos a una coyuntura política en la que un expresidente con mandato finalizado mantiene unido a su movimiento y, además, controla parte del poder político institucional con pretensiones de definir las candidaturas de su partido de cara a las elecciones del año 2023. Asimismo, de forma paradójica, mientras por un lado Cartes incentiva el juego de los juicios políticos, por el otro construye una alianza política llamada «Concordia Colorada» con el Movimiento Añetete del presidente Mario Abdo, intentando así la subordinación a su persona del conjunto de los movimientos colorados.

También es cierto que, si retomamos la explicación que hicimos más arriba sobre el funcionamiento de la regla de distribución proporcional del poder a través de la fórmula D’Hondt, esta genera incentivos para la competencia intrapartidaria y la creación de nuevos movimientos, ya que motiva a los principales líderes políticos a establecer sus propias facciones para competir en elecciones internas, las que finalmente resultan en una lista unificada para las elecciones generales. En otras palabras, la regla de distribución proporcional podría impedir que Cartes logre el dominio de los movimientos colorados por subordinación.

Esta regla de distribución proporcional del poder político institucional ha funcionado durante dos décadas para mantener una fuerte dis- 
puta interna dentro de la ANR, en una correlación de equilibrio de fuerzas débiles. Por esta razón, en esta coyuntura, nos preguntamos si estamos asistiendo a un cambio de esas reglas o, por el contrario, serán las reglas proporcionales las que logren mantener el equilibrio de la competencia, tanto a nivel interno como a nivel nacional.

\section{Cierre y coyuntura de cara a las elecciones presidenciales de 2023}

En la actual coyuntura política, el poder político institucional pasa específicamente por el Movimiento Honor Colorado, de Horacio Cartes, y hasta el momento no ha surgido un nuevo movimiento dentro del Partido Colorado con capacidad para convertirse en una fuerza nacional que pueda disputarle la conducción de cara a las elecciones del 2023. Es más, la primera fuerza de la oposición, el PLRA, se encuentra dividida y atravesada por el Cartismo. De hecho, uno de sus dos movimientos más importantes, el Movimiento Equipo Joven, liderado por Blas Llano, es conocido como «libero-cartista» por su constante cooperación con las posturas que el movimiento conducido por Cartes sostiene en el Congreso.

En términos electorales y de poder político institucional, el PLRA continúa siendo el más importante de los partidos de la oposición, tanto en votos como en estructura partidaria, asientos legislativos y conducción de departamentos ${ }^{13}$ y municipalidades. No obstante, no tiene capacidad para derrotar a la ANR en la política nacional sin aliarse al «tercer sector político», tal como se ensayó en 2008 con Fernando Lugo.

La conducción y composición del tercer sector ha variado desde el inicio de la transición democrática. En los años 1990 estuvo conducido por la Partido Encuentro Nacional, en los años 2000, por los partidos de derecha Patria Querida y UNACE y, a partir del 2013, por la alianza de izquierda Frente Guazú. Sin embargo, desde 2018, en un contexto regional de mayor auge neoliberal, observamos la vuelta y el ascenso del Partido Patria Querida.

Sin embargo, en esta coyuntura, la novedad dentro de la oposición nacional es el surgimiento de dos nuevos actores -senadores desde 2018-

\footnotetext{
${ }^{13}$ Paraguay es un país unitario divido en departamentos. A su vez cada departamento tiene distritos (municipalidades). Cada Departamento tiene un gobernador y concejales departamentales, y los municipios o distritos, intendentes y concejales municipales.
} 
despojados de instituciones partidarias tradicionales y con cierta capacidad para intentar liderar la intención de voto: Paraguayo (Payo) Cubas, con su partido Cruzada Nacional, y Kattya González. El primero, desde un formato bastante caricaturesco, denunció constantemente a toda la clase política hasta que fue destituido. Kattya González, si bien ingresó a la Cámara de Senadores con el Partido Encuentro Nacional, recogió votos principalmente por su figura individual.

Ambos mantienen aspiraciones presidenciales para el 2023. Payo Cubas ya está en campaña y se ha mostrado muy reacio a generar alianzas con los partidos de la oposición, postura con la que saca su mayor redito político. Por su parte, Kattya González tiene una postura más abierta a las posibles alianzas, aunque critica constantemente al Partido Colorado y al Partido Liberal e incluso ha apuntado contra el mismo presidente del PLRA, Efraín Alegre, quien es a su vez uno de los principales líderes opositores.

Fuera de lo estrictamente partidario, en marzo de 2021 Paraguay vivió jornadas de manifestaciones contra las políticas del Gobierno. Un grupo importante de personas se volcó a las calles con una multiplicidad de demandas, disparadas por la precariedad del sistema de salud y la falta de vacunas en el contexto de una pandemia que coloca a todos los liderazgos políticos en situación de crisis. Ahora, y si bien es cierto que en estas movilizaciones una de las consignas que logró posicionarse fue la de «ANR nunca más», también es correcto afirmar que las manifestaciones fueron apoyadas y fogoneadas por el movimiento de Horacio Cartes, con consignas como «Estoy para otro marzo paraguayo». El trasfondo fue otra vez más el juicio político al presidente Mario Abdo. Como en el 2019, pero también como tantas veces en la historia del país, el presidente quedó al borde de la destitución.

\section{Referencias bibliográficas}

Abente Brun, D. (Coord.). (1993). Paraguay en transición. Caracas, Venezuela: Nueva Sociedad.

Delich, F. (1981). Estructura agraria y hegemonía en el despotismo republicano paraguayo. Estudios Rurales, 4(3), 239-255.

Demelenne, J. (2021). Una interpretación de la historia política contemporánea del Paraguay a partir de la lectura de los golpes de Estado 
(1947-2012). En P. R. da Silva y L. Soler (Coord.), Stronismo. Nuevas lupas. Foz de Iguazú, Brasil: UNILA (en prensa).

González Bozzolasco, I. y Martínez Escobar, F. (2019). Los procesos políticos-electorales de la izquierda paraguaya en los 30 años de democracia. E-1@tina. Revista electrónica de estudios latinoamericanos,17(68), 55-74. Recuperado de https://publicaciones. sociales.uba.ar/index.php/elatina/article/view/4401

Lara Castro, J. (1992). Paraguay: la transición incierta. En L. Meyer y J. L. Reyna (Coord.), Los sistemas politicos en América Latina, (pp. 107-126). México, México: Siglo XXI.

Martínez Escobar, F. (2021). De la caida de Stroessner a la destitución de Lugo (2008-2013): partidos progresistas y sistema de partidos en el Paraguay. Tesis para optar por el título de Doctor. Buenos Aires, Argentina: Facultad de Ciencias Sociales de la Universidad de Buenos Aires.

Moore, B. (2002). Los orígenes sociales de la dictadura y de la democracia. El señor y el campesino en el mundo moderno. Barcelona, España: Península.

Prego, F. (2019): Poststronismo, reforma constitucional y transición democrática. La construcción de una nueva legalidad en Paraguay. Sociohistórica, (43), e072. doi: https://doi.org/10.24215/1852 1606e 072

Soler, L. (2012). La larga invención del golpe. El stronismo y el orden politico paraguayo. Buenos Aires/Montevideo, Argentina/Uruguay: Imago Mundi/CEFIR.

Yore, M. (2015): Presidencialismo y transición democrática. El caso paraguayo en los 90. Asunción, Paraguay: FLACSO. 